\title{
A formação de acadêmicos de Enfermagem no contexto Amazônico: as populações
}

\section{negras e quilombolas}

\author{
The training of Nursing academics in the Amazon context: the black and quilombola populations \\ La formación de los académicos de Enfermería en el contexto Amazónico: las poblaciones negra y \\ quilombola
}

\section{Resumo}

Neste artigo, objetiva-se refletir sobre a formação dos acadêmicos de enfermagem das Instituições de Ensino Superior (IES) da região do oeste do Pará no tocante a assistência integral à saúde das populações negras/quilombolas. É uma pesquisa descritiva, com abordagem qualitativa. Os participantes do estudo foram professores e acadêmicos de enfermagem de duas IES de Santarém-PA. Foram realizadas entrevistas individuais e utilizou-se o software IRAMUTEQ para avaliação das falas, através da ferramenta Classificação Hierárquica Descendente, para avaliação qualitativa e quantitativa. Constatou-se que tanto professores quanto acadêmicos têm conhecimentos básicos sobre a Política Nacional de Saúde Integral da População Negra (PNSIPN) e sobre as peculiaridades do modo de vida desta população. Verificou-se também que as IES ainda têm dificuldade em colocar em prática a proposta do Projeto Pedagógico do Curso (PPC), que é uma ferramenta de planejamento e avaliação pedagógica que norteia as diretrizes curriculares dos cursos de enfermagem.

Palavras-chave: População Negra e Quilombola; Enfermagem; Educação Superior; Ensino.

\begin{abstract}
In this article, the objective is to reflect on the training of nursing students from Higher Education Institutions (HEIs) in the western region of Pará with regard to comprehensive health care for black/quilombola populations. It is a descriptive research with a qualitative approach. The study participants were nursing professors and academics from two HEIs in Santarém-PA. Individual interviews were conducted and the IRAMUTEQ software was used to assess the speeches, through the Descending Hierarchical Classification tool, for qualitative and quantitative assessment. It was found that both professors and academics have basic knowledge about the National Policy for Comprehensive Health of the Black Population (PNSIPN) and about the peculiarities of this population's way of life. It was also found that HEIs still have difficulty in putting into practice the proposal of the Pedagogical Course Project (PPC), which is a pedagogical planning and evaluation tool that guides the curricular guidelines of nursing courses.
\end{abstract}

Keywords: Black Population and Quilombola; Nursing; College Education; Teaching. 


\section{Resumen}

En este artículo, el objetivo es reflexionar sobre la formación de los estudiantes de enfermería de las Instituciones de Educación Superior (IES) de la región occidental de Pará en lo que respecta a la atención integral de la salud de la población negra / quilombola. Es una investigación descriptiva con enfoque cualitativo. Los participantes del estudio fueron profesores de enfermería y académicos de dos IES en Santarém-PA. Se realizaron entrevistas individuales y se utilizó el software IRAMUTEQ para evaluar los discursos, a través de la herramienta de Clasificación Jerárquica Descendente, para la evaluación cualitativa y cuantitativa. Se encontró que tanto profesores como académicos tienen conocimientos básicos sobre la Política Nacional de Salud Integral de la Población Negra (PNSIPN) y sobre las peculiaridades del modo de vida de esta población. También se encontró que las IES aún tienen dificultades para poner en práctica la propuesta del Proyecto de Curso Pedagógico (PPC), que es una herramienta de planificación y evaluación pedagógica que orienta los lineamientos curriculares de los cursos de enfermería.

Palabras clave: Población Negra y Quilombola; Enfermería; Educación Universitária; Enseñanza.

\section{Introdução}

O ensino para formação do profissional de saúde tem sido marcado, historicamente, pela fragmentação e pela visão hospitalocêntrica, biologista, sustentando um modelo tradicional de ensino, na lógica da educação bancária, que enfatiza a superespecialização e a sofisticações de ações e procedimentos coletivos. Esta realidade tem dificultado o processo de ensino e aprendizagem, o qual centra-se na formação tecnicista, concebendo o professor como detentor do saber técnico-científico (Keller-Franco, Kuntze \& Costa, 2012).

Há um reforço do processo de ensino em uma perspectiva hierarquizada, contrapondo-se ao ensino por resolução de problemas, contribuindo assim, para a formação de profissionais despreparados para atuação nos serviços de saúde (Moraes \& Costa, 2016).

Neste sentido, considera-se um desafio, construir um ensino voltado para o conhecimento integrado e contextualizado, articulando teoria e prática, com uma proposta concreta de integração do ensino e exercício profissional em seus contextos socioeconômico-político-cultural. Acredita-se que este é o caminho para preparar, construir e sensibilizar os alunos para ações de prevenção, promoção, proteção e reabilitação, tanto individual como coletiva, primando pela qualidade técnico-científica, princípios éticos e de responsabilidade social. Uma formação com estas características tem condições de contribuir positivamente para as mudanças de atitudes e habilidades profissionais nos cenários dos serviços de saúde (Santos \& Tocantins, 2015).

Neste contexto, as Diretrizes Curriculares Nacionais (DCN's) do curso de enfermagem, aprovadas por meio da Resolução $\mathrm{n}^{\circ} 03$ de 7 de novembro 2001, determinam que os currículos atendam às necessidades sociais da saúde, com ênfase no Sistema Único de Saúde (SUS). Isso significa assegurar uma formação que considere prioritário os princípios do SUS, como a integralidade, a universalidade e a equidade na tenção em saúde, primando pela qualidade e humanização do atendimento, em consonância com uma visão ampla do processo de saúde voltada ao cidadão, família e comunidade em geral (Silva \& Santana, 2015).

É preciso também ampliar essa discussão sobre os princípios do SUS, no tocante a população negra, dando visibilidade a estudos sobre a temática, promovendo e apoiando o desenvolvimento de ações em saúde voltada para este grupo populacional (Santos \& Tocantins, 2015). De acordo com o último censo, realizado pelo Instituto Brasileiro de Geografia e Estatística (IBGE-2010), demostrou-se que a quantidade de pessoas que se autodeclaram pardas ou negras foi de $43,1 \%$ e de 7,8\%, respectivamente. Portanto, perfazendo mais de 50,7\% da população brasileira (Chehuen Neto, et al., 2015).

No Sistema Nacional de Notificação de Nascidos Vivos (SINASC) e no Sistema de Informação de Mortalidade (SIM), os quais apontam que a maior proporção de nascidos vivos em mães adolescentes está entre as mães negras e indígenas e as maiores taxas de mortalidade materna é de mulheres negras, a qual encontra-se associada à falta de acesso ao pré-natal e ao parto com assistência inadequada, bem como a possíveis complicações derivadas da hipertensão ou das doenças falciforme não detectada pelos serviços de saúde, o que evidencia que nesta população de pardos e negros, há um diferencial nas 
condições de viver, adoecer e morrer. (Batista, Werneck \& Lopez, 2012).

Dentre as políticas do SUS, a Política Nacional de Saúde Integral da População Negra (PNSIPN), instituída pela Portaria GM MS nº 992 de 13 de maio de 2009, busca garantir a equidade e a efetivação do direito à saúde aos afro-brasileiros. Tendo como marco o reconhecimento do racismo, das desigualdades étnico-raciais e do racismo institucional, como determinantes sociais das condições de saúde, estabelecendo diretrizes, estratégias e responsabilidades da gestão em todas as esferas de governo (Brasil, 2017).

A informação sobre saúde de culturas locais e povos afrodescendentes ainda é muito limitada na América latina, sendo os índices socioeconômicos e as diferenças culturais um forte determinante para a qualidade da saúde desta população, a exemplo do estudo de Soares et al. (2020) no Estado do Piauí, realizado em comunidades quilombolas, constatou que o percentual de residências que apresentavam pouca ou nenhuma condição sanitária $(74,1 \%)$ foi consideravelmente maior que os que declararam possuir condição sanitária satisfatória.

Portanto, verifica-se que existem políticas e diretrizes que norteiam as ações e serviços de saúde direcionada as necessidades da população negra/quilombola, a partir dos princípio do SUS, contudo é preciso verificar como estas políticas tomam o corpo no processo de formação dos profissionais de saúde, e neste caso específico na formação do enfermeiro, diante desta realidade buscou-se como problema de estudo o seguinte: Que formação os acadêmicos de enfermagem das Instituições de Ensino Superior (IES) da região do oeste do Pará, estão recebendo, para desenvolver assistência integral as populações negra/quilombolas?

\section{Metodologia}

O estudo teve uma abordagem qualitativa buscando, apreender a soma de conhecimentos acerca dos fatos estudados, valorizando as falas dos participantes e respeitando a profundidade dos discursos proferidos valorizando a percepção dos sujeitos envolvidos, com foco nos significados atribuídos aos fenômenos da realidade social (Pereira et al., 2008).

A pesquisa foi desenvolvida em um município situado na região Oeste do Estado do Pará, na mesorregião do Baixo Amazonas. Nesta região existem 04 IES que ofertam a graduação em Enfermagem de forma presencial. Das quatro IES focouse o estudo em duas por apresentarem no seu projeto pedagógico do curso a disciplina que aborda a assistência de enfermagem às populações tradicionais da Amazônia.

Os participantes da pesquisa foram 20 acadêmicos concluintes do curso de enfermagem e 13 professores das IES selecionadas. A seleção destes participantes se deu a partir dos seguintes critérios: acadêmicos do último ano do curso de enfermagem das IES selecionadas e professores com experiência na docência do ensino superior por pelo menos três anos, com vínculo de no mínimo um ano e meio com a instituição. A pesquisa adotou o critério de saturação para interromper o estudo para todos, também foi considerado o aceite do convite mediante assinatura do Termo de Consentimento Livre e Esclarecido (TCLE) e o estudo foi aprovado pelo Comitê de Ética em Pesquisa da Universidade do Estado do Pará, sob o parecer n. 1.900.497, CAAE 58030116.6.0000.5209.

Para a coleta de dados, utilizou-se entrevistas abertas, direcionada aos professores e acadêmicos, no período de fevereiro a junho de 2019, nas instituições de ensino de origem de cada participante. Para análise do material lexigráfico foi usado o software IRAMUTEQ, que é um software utilizado em pesquisas qualitativas para analisar grandes textos, auxiliando na organização e separação de informações, gerando eficiência do processo e facilidade na localização dos segmentos de texto, além de possibilitar agilidade no processo de codificação em comparação ao processo de análise realizado à mão (Souza et al., 2018).

A análise dos dados nas entrevistas dos professores, apresentou um aproveitamento de 72,97\% de Segmentos de Textos (ST) e 81,04\% para os dados dos acadêmicos. Na sequência rodou-se o corpus na análise de Classificação Hierárquica 
Descendente (CHD) e feito avaliações quantitativa e qualitativa das falas dos entrevistados.

A CHD foi proposta por Reinert (1990) que classifica os segmentos de texto em função dos seus respectivos vocabulários, e o conjunto deles é repartido com base na frequência das formas reduzidas. Esta análise visa obter classes de Unidades de Contextos Elementares (UCE) que, ao mesmo tempo, apresentam vocabulário semelhante entre si e vocabulário diferente das UCE das outras classes. Cada Classe da CHD é representada por uma cor e se associa a um ST também separado por cor. Os ST que representa cada classe também é separado em um arquivo denominado "corpus colorido", produzido pelo software.

\section{Resultados e discussão}

\section{Corpus I - Entrevistas com os professores}

O corpus I produziu a Figura 1 com divisão em (5) classes, representado pela figura Corpus I. Após a CHD, teve aproveitamento de análise total do texto de 72,97\%, separando em 18 (ST). O conteúdo analisado foi dividido em cinco classes apresentadas a seguir, com as palavras de maior ocorrência, ou seja, que obtiveram um valor de $\mathrm{P}<0,0001$ :

- Classe (1): cor vermelha, com 17 ST, correspondendo a 15,77\%;

- Classe (2): cor cinza, com 25 ST, representando $23,1 \%$;

- Classe (3): cor verde, com 22 ST, representando 20,4\%;

- Classe (4): cor azul, com 25 ST, representando 23,1\%;

- Classe (5): cor lilás, com 19 ST, representando 17,6\%.

Figura 1 - Dendograma dos Professores.

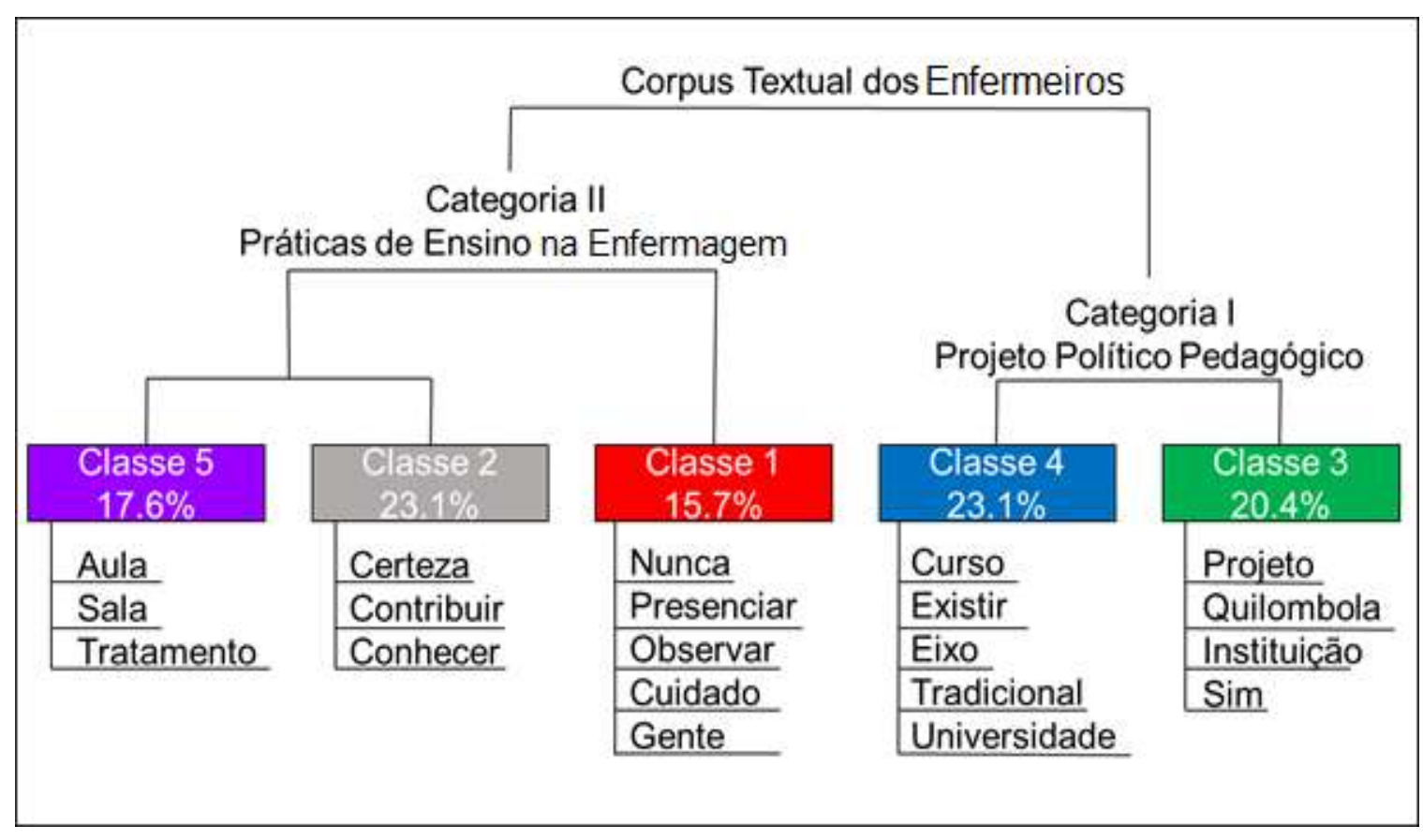

Fonte: Protocolo de pesquisa (2020). 


\section{Categoria Temática I: Projeto Pedagógico do Curso}

$\mathrm{Na}$ classe (3) cor verde e classe (4) cor azul, referem-se as perguntas que geraram a categoria: 1) O projeto Pedagógico do Curso prevê disciplina/atividade e/ou abordagens pedagógicas voltadas à saúde da população negra $\mathrm{e}$ quilombola? Fale sobre. 2) Na formação do enfermeiro, você considera necessário, abordar as especificidades de saúde de populações negras e quilombolas? Fale sobre as suas especificidades.

Verificou-se que as palavras em destaque nos fragmentos das entrevistas dos professores, que apresentaram maiores ocorrências foram: projeto; quilombola; instituição; sim; curso; existir; eixo; tradicional; universidade.

"eu creio que seja uma carga horária pequena para discutir a temática no curso, pois esta abordagem direcionada a saúde da população negra/quilombola, que é uma sub-temática dentro de projeto político pedagógico de 5 anos" P01.

"não tenho conhecimento dessa população, até porque a disciplina que ministro, ocorre no $2^{o}$ semestre, não tenho conhecimento do se trabalha nos eixos posteriores" P07.

"sim, certamente, é muito importante, apesar do Projeto do curso, não trazer uma linha específica, a não ser dentro dos eixos, que tem um tópico, muito simplório” P13.

"sim, aqui, na instituição, além de estar na grade a disciplina saúde das populações quilombolas, eles trabalham nos projetos na comunidade..." P11.

“sim, nós já desenvolvemos ações e atendimentos voltados para esses pacientes...” P10.

"sou professora do $6^{\circ}$ semestre, não tenho conhecimento preciso de todas as disciplinas do projeto do curso da instituição” P01.

"as atividades de pesquisa, se existir são pontuais de algum professor, que é pesquisador, mas desconheço estágios direcionado a saúde da população negra/quilombola”. P 01.;

“....no projeto político pedagógico do curso é um disciplina voltada para assistência de saúde para as populações tradicionais”. P 03.

“....e pra dizer a verdade, o projeto pedagógico, no sentido geral eu não li...” P 09.

“...sei, que existe no eixo, no quarto ano a disciplina que trabalha as populações tradicionais, mas não tenho muito conhecimento dessa população...” P 07.

“...dentro da universidade tem um eixo temático que ensina sobre os povos tradicionais” $P 04$.

Conforme as falas que representam as classes azul e verde, percebe-se que os professores não participam da sua construção e tampouco conhecem as políticas públicas de saúde direcionadas a população negra. Esta realidade é preocupante, uma vez que o êxito do processo formativo depende do alinhamento entre a equipe de professores, a estrutura organizacional e as propostas pedagógicas do curso.

Estas propostas devem estar de acordo com as orientações das Diretrizes Curriculares Nacionais para a formação em enfermagem, que prevê autonomia das IES para elaborar a sua proposta pedagógica, indicando que esta deve ser feita de forma a garantir a participação de todos os envolvidos no processo ensino-aprendizagem (Spessoto, Real \& Bagnato, 2012; Ganassin, 2015).

O Projeto Pedagógico do Curso é um processo dinâmico, contínuo e flexível, dotado de um conjunto de ações coletivas que visam realizar mudanças estruturais na organização pedagógica nas instituições de ensino superior. Exige dos seus atores comprometimento permanente com a transformação das práticas pedagógicas, rompendo com as práticas cristalizadas e enfrentando os desafios, para possibilitar uma formação que contemple as necessidades de saúde dessa população (Magalhães et al., 2017). 
Destaca-se que mesmo com todas as orientações do Ministério da Educação e das políticas públicas de saúde do SUS, as IES têm dificuldade em colocar em práticas propostas mais ousadas em seus Projetos Pedagógico de curso, devido a dinâmica organizacional, estrutural e os recursos humanos envolvidos neste processo.

\section{Categoria Temática II: Prática de Ensino na Enfermagem}

Nesta categoria representam as classes (1) vermelha, (2) cinza e (5) lilás do dendrograma da figura dos corpus analisados. Nas falas da classe (5) cor lilás os professores entrevistados referem-se as questões do dendrograma: Na sua prática pedagógica você desenvolve atividade e discussões e/ou estratégias, voltadas a saúde das populações negras e quilombolas? Como isso se dá? O que você pensa sobre a adesão a tratamentos alternativos provenientes do saber cultural de populações negras e quilombolas? Nas atividades práticas de enfermagem com os acadêmicos, você já presenciou comportamentos e atitudes discriminatórios? Relate.

Verifica-se que as palavras em destaque, nos fragmentos abaixo das entrevistas dos professores, as palavras que apresentaram maiores ocorrências; aula; sala; tratamento.

“...só mesmo discussões surgem sobre a saúde da população negra na sala de aula, a partir de algum texto lido, mas nenhum trabalho especifico" P09.

"eu indico, e inclusive é previsto no ministério da saúde o plantio dos medicamentos fitoterápicos" P06.

"Tratamento alternativos, é algo que se tem de respeitar, por que o conhecimento empírico dele agrega o nosso conhecimento cientifico, e que devemos respeitar" P10.

"a gente desenvolve mais a parte teórica, nunca tive a oportunidade de viajar para essas comunidades, mas respeito e defendo os tratamentos alternativos" P13.

Em geral, os professores se sentem responsáveis em promover debates e discussões em sala de aula dos temas que estão presentes em seu componente curricular. As dificuldades em abordar questões problemáticas, que influenciam na sociedade, nos diferentes processos de adoecimento e planejamento de cuidados em saúde, tem relação com a estrutura, com a proposta do processo de formação e com a falta de conhecimento do PPC e desinformações históricas e epidemiológicas deste grupo.

Para uma formação mais generalista e efetiva, com foco no atendimento aos princípios do SUS, é necessário que os professores envolvidos com a formação do enfermeiro tenham uma visão ampliada do processo saúde e doença, contrapondo-se as teorias de saúde cristalizadas, defendendo a saúde como processo construído no contexto histórico e social de cada época e sociedade, refletindo a condição social, econômica, política e cultural de cada grupo (Peres et al., 2018).

Na classe (2) cor cinza, verifica-se as palavras em destaque, nos fragmentos abaixo das entrevistas dos professores, em que apresentaram maiores ocorrências: certeza; contribuir; conhecer.

"os tratamentos alternativos na saúde, são importantes para valorizar a cultura de saúde nas comunidade e contribuir na qualidade de vida dessa população" P01.

"acho importante conhecer a realidade local, pois estamos num cenário que exige, que o enfermeiro tenha esta formação diferenciada" P03.

"há necessidade de você conhecer a cultura desses povos e respeitar" P 06. 
"com certeza, fomentar as ideias das políticas públicas de saúde para contribuir na atuação em saúde para esta população.” P13.

Verifica-se que os professores participantes do estudo, concordam com a necessidade do futuro profissional da enfermagem, conhecer a realidade local e cultural das populações negras, a fim de poder contribuir com a saúde e qualidade de vida deste grupo. Percebem a necessidade de valorizar as práticas tradicionais de cuidado com a saúde, visto que, estas práticas estão presentes nas comunidades quilombola, estão disponíveis e de fácil acesso.

Para tanto, as DCN's orientam que a educação de profissionais de saúde integre conteúdo da PNPIC, em um contexto de ensino plural que ofereça um conjunto de perspectivas críticas de modelos terapêuticos e permita que estudantes façam uso de diferentes paradigmas em saúde para lidar com os processos de adoecimento na sociedade contemporânea.

Neste sentido, faz-se necessário que as instituições formadoras de profissionais da saúde, em específico de formação do enfermeiro, assumam o compromisso de preparar o futuro profissional para compreender que as práticas populares de cuidado, enquanto práticas sociais, ocorrem no encontro entre diferentes sujeitos e se identificam com uma postura mais integradora, que reconhece e legitima crenças, valores, conhecimentos, desejos e temores da população (Bagata, 2018).

Os professores participantes do estudo relatam que concordam com as práticas tradicionais de saúde, mas que o processo de formação precisa ser revisto quanto a esta temática. Porém, é necessário garantir formação permanente aos docentes para que tenham conhecimento aprofundado das políticas públicas que abordam essas especificidades da saúde da população negra, de metodologias de aprendizagem que permitam aproximar o aluno da realidade objetiva e da possibilidade interdisciplinar para compreender, de forma ampla, os processos de adoecimento da população.

$\mathrm{Na}$ classe (1) vermelho, verifica-se que as palavras em destaque, nos fragmentos abaixo das entrevistas dos professores, apresentaram maiores ocorrências: nunca; presenciar; observar; cuidado; gente.

"eu acho necessário ampliar esta discussão, relacionado ao cuidado a esta população, eu observo que a integralidade nos atendimentos de saúde não estão ocorrendo" P07.

“... pelo olhar, agente observa a discriminação...” P04.

“em relação a discriminação, nunca presenciei comportamentos discriminatórios" P03.

“...eu nunca presencie preconceitos com a pessoa negra/quilombola” P05.

“...é necessário ampliar essa discussão em relação ao cuidado, pois, ainda não acontece” P04.

“...esse cuidado, deve ser desenvolvido na atenção primária” P11.

"e na atenção primária que a gente mais espera esse atendimento" P13.

“o ser humano é igual a todos, na verdade nunca presenciei comportamento discriminatórios" P08.

Os professores dos cursos de enfermagem, em sua maioria, não percebem preconceitos e nem atitudes discriminatórias às pessoas negras nos ambientes de saúde. Talvez isto ocorra por não estarem atentos/sensíveis para observar ou identificar o racismo, pode ser que determinadas práticas já tenham sido naturalizadas e por isso não são identificadas como preconceito ou, ainda, pela cultura de negação do reconhecimento do racismo no cotidiano do atendimento à saúde. Outra possibilidade é a não atuação efetiva destes profissionais nos cenários de práticas. 
O Brasil é considerado um país preconceituoso, entretanto, os indivíduos não se assumem como preconceituosos, essa postura de negação do preconceito está presente no cotidiano, através de comportamentos sutis e disfarçados, podendo produzir humilhação social e sofrimento psíquico nos indivíduos, e comprometer a qualidade de vida do cidadão (Brito $e t$ al., 2017).

Diante deste cenário, considera-se necessária a inclusão da disciplina/eixo temático "educação das relações étnicoraciais" no curso de enfermagem, como um possível caminho para implementação de uma política curricular, que contemple, com maior amplitude, a discussão sobre as iniquidades em saúde ocasionada pelo racismo. Da mesma forma, é necessário sensibilizar e capacitar o profissional que irá assumir a disciplina/eixo temático, a fim de sensibilizá-lo para uma proposta didático-metodológica que aborde o cuidado de forma ampla, em especial da população negra/quilombola, alinhando sua atuação com que prevê a PNSIPN (Mendes, Costa \& Ribeiro, 2015; Faria \& Silva, 2016).

\section{Corpus II - Entrevistas com os Acadêmicos de Enfermagem}

O Corpus II refere-se às entrevistas com os acadêmicos de enfermagem (Figura 2), cujo CHD apresentou um aproveitamento de $81,04 \%$ do texto, dividindo em 218 ST. O conteúdo analisado foi dividido em cinco classes:

- classe (1) de cor vermelha, com 47 ST, representou $21,56 \%$ do total de texto;

- classe (2) de cor cinza, com 46 ST, representou $21,16 \%$ do texto;

- classe (3) de cor verde, com 33 ST, representou $15,14 \%$ do texto;

- classe (4) de cor azul, com 46 ST, com $21,1 \%$ no texto analisado;

- classe (5) de cor lilás, com 46 ST e com 21,1\% em relação ao texto analisado.

Figura 2 - Dendograma dos acadêmicos de enfermagem.

\begin{tabular}{|c|c|c|c|c|}
\hline & $\begin{array}{r}\text { Corpu } \\
\text { FormaçãoA }\end{array}$ & $\begin{array}{l}\text { Textual dos a } \\
\quad \text { । } \\
\text { mica dos En }\end{array}$ & $\begin{array}{l}\text { êmicos } \\
\text { neiros }\end{array}$ & \\
\hline $\begin{array}{c}\text { Conhecimentos } \\
\text { da PNSINPN } \\
\text { Classe ? }\end{array}$ & $\begin{array}{r}\text { Conhecim } \\
\text { da pope }\end{array}$ & $\begin{array}{l}\text { culturais } \\
\text { negra }\end{array}$ & $\begin{array}{l}\text { Experiências } \\
\text { discriminatórias }\end{array}$ & Práticas \\
\hline $21.1 \%$ & & & & acadêmicas \\
\hline Agora & $\begin{array}{c}\text { Classe } 3 \\
15.1 \%\end{array}$ & $\begin{array}{c}\text { Classe } 1 \\
21.6 \%\end{array}$ & $\begin{array}{c}\text { Classe } 5 \\
21.1 \% \\
\end{array}$ & $\begin{array}{c}\text { Classe } 4 \\
21.1 \% \\
\end{array}$ \\
\hline $\begin{array}{l}\text { Fator } \\
\text { Doença } \\
\text { Histórico } \\
\text { Lembrar } \\
\text { Lei } \\
\text { Mais } \\
\text { Direito } \\
\text { Existir } \\
\text { Negro } \\
\text { Hipertensão } \\
\text { Contexto } \\
\end{array}$ & \begin{tabular}{|l} 
Tratamento \\
Medicinal \\
Quando \\
Gostar \\
Coisa \\
Planta \\
Aceitar \\
Escutar \\
Sempre \\
\end{tabular} & $\begin{array}{l}\text { Importante } \\
\text { Lidar } \\
\text { Cultura } \\
\text { Branco } \\
\text { Acreditar } \\
\end{array}$ & \begin{tabular}{|l|} 
Pessoa \\
Família \\
Presenciar \\
Certo \\
Aqui \\
Santarém \\
\end{tabular} & \begin{tabular}{|l|} 
Projeto \\
Quilombo \\
Saúde \\
Levar \\
Ação \\
Comunidade \\
Contato \\
Quilombola \\
Vivência \\
\end{tabular} \\
\hline
\end{tabular}

Fonte: Protocolo de pesquisa (2020). 
Após analisar o resultado das partições do dendograma e analisar o corpus colorido produzido pelo software, a classe (2) cinza refere-se à PNSIPN; a classe (4) azul refere-se às práticas acadêmicas; a classe (5) lilás faz referência as experiências discriminatórias, e as classes vermelha (1) e verde (3) referem-se aos conhecimentos culturais da população negra.

\section{Conhecimento sobre a Política Nacional de Saúde Integral da População Negra (PNSIPN)}

A classe dois (2) cor cinza, foi gerada pelas perguntas que geraram esta categoria: Para você, quais são os aspectos específicos de adoecimento de população negra e quilombola? Você conhece alguma legislação que garante a assistência integral a saúde da população negra e quilombola? Fale sobre a política e o que você pensa sobre isso;

Verifica-se as palavras em destaque, nos fragmentos abaixo das entrevistas dos acadêmicos. As palavras que apresentaram maiores ocorrências: agora; fator; doença; histórico; lembrar; lei; mais; direito; existir; negro; hipertensão; contexto.

“...Agora não estou lembrando, mas sei que existe uma lei que garante o direito uma assistência de saúde, a saúde das populações negra” A03.

“...já estudei sobre a temática e aprendi que a população negra são mais suscetíveis á algumas doenças, mas agora não consigo lembrar" A04.

“... as mulheres negras sofrem mais abuso sexual” A04.

“...pelo contexto histórico do nosso país, a população negra foi muito prejudicada” A09.

“pelos meus estudos, eu pude perceber a doença que mais afeta os negros é a hipertensão, diabetes” A17.

"A população negra é mais suscetível para apresentar anemia falciforme, pelo fator genético, e os fatores ambientais contribui para outros agravos à saúde, pela questão sócio-econômica” A14.

Os acadêmicos demonstram ter tido em sua formação, algumas informações acerca da saúde das populações negras, inclusive com citação da política pública que a normatiza, contudo, percebe-se a fragilidade deste conhecimento e nenhuma atividade prática ou de aproximação com a realidade deste grupo foi relatada. Em uma das instituições em que é ofertada a disciplina Enfermagem nas populações tradicionais, percebeu-se que a carga horária destinada a prática é muito reduzida e, dependendo do profissional que assume a disciplina, ela não é revertida em visitas efetivas ou aproximações da realidade objetiva pelos acadêmicos.;

A PNSIPN, foi uma medida compensatória na área de saúde, na tentativa de minimizar os efeitos da discriminação e da exploração sofridas pelos negros ao longo da história brasileira. Nesta política o destaque para a equidade se dá em virtude da necessidade de diminuir as desigualdades, contudo, não deve ser considerado sinônimo de igualdade. Mesmo que a constituição federal, o SUS e a PNSIPN garantam o acesso aos serviços de saúde a todos independente de sua cor condição sócio -econômica e religiosa, tem-se que considerar que as pessoas possuem necessidades distintas.

Mesmo diante disso, Santana et al. (2019), afirmam que a abordagem da saúde integral da população negra ainda encontra dificuldade para se consolidar nos currículos de cursos da saúde. Apesar de ser contemplada na formação de muitas instituições de ensino, ainda se apresenta com pouca visibilidade, vista de forma obrigatória e impositora por parte do Ministério de Saúde, sem reconhecer sua importância para o debate amplo da saúde. 


\section{Conhecimentos Culturais da População Negra}

As classes (1) vermelho e (3) verde, após a análise do corpus que gerou esta categoria foram: considerando a atuação com este grupo específico, negros/quilombolas, o que você pensa sobre tratamentos alternativos provenientes dos saberes culturais?

Na Classe (1) cor vermelha, as palavras que apresentaram maiores ocorrências foram: importante; lidar; cultura; branco; acreditar; Na classe (3) cor verde, correspondendo a, as palavras que apresentaram maiores ocorrências foram; tratamento; medicinal; quando; gostar; coisa; planta; aceitar; escutar; sempre.

“... gosto muito de trabalhar com a medicina tradicional” A01.

“... usar algumas plantas e alguns meios de tratamento deles é muito legal, sempre escuto, porque para mim eu acho que é aprendizagem, que eu estou repassando para eles uma coisa que eu aprendi e eles estão me trazendo" A04.

"eu acho que é válido por que eu tenho a crença que não só o tratamento com base na medicina, o tratamento biomédico, eles fazem efeitos curativos na população eu tenho crenças em receitas caseiras” A09.

"eu acho de extrema importância até por que eles tem a própria cultura deles, e principalmente pela questão medicinal” A17.

“Você tem que respeitar, mesmo sem concordar com esse tipo de tratamento medicinal” Al8.

“... a gente sempre tem que aceitar porque é do costume da cultura deles”. A18.

Os relatos dos acadêmicos demonstram que eles respeitam o tratamento de saúde seguindo saberes da cultura tradicional e concordam com seu uso no apoio ao tratamento medicamentoso. Eles reconhecem a necessidade de agregar este conhecimento tendo em vista a política nacional de plantas medicinais e fitoterápicas no SUS. Consideram também que esta abordagem precisa ser mais discutida em sala de aula e nas vivências de prática, pois ainda existem muitas dúvidas quanto à eficácia de seu uso. Muitos acadêmicos não estão habituados com esta realidade, por isso a necessidade de garantir espaços adequados em sua formação para problematizar e refletir limites e possibilidades da articulação dos diferentes tratamentos/procedimentos no cuidado em saúde.

Pode-se dizer que a enfermagem é essencialmente uma profissão de cuidados transculturais, tendo em vista a diversidade de culturas e hábitos de vida dos diferentes grupos humanos que atende cotidianamente. Neste sentido, considerando as diferenças expressas pelos modos de viver, de ser e agir da população negra referente aos cuidados de saúde. Para uma atuação efetiva e integral, os enfermeiros precisam ir além da competência técnica. É necessário valorizar a cultura, os valores, as crenças e os costumes dos grupos sociais no tocante à saúde, admitindo-se também as práticas locais, domésticas e tradicionais como prática de cuidados de saúde (Pinheiro et al., 2015).

\section{Práticas Acadêmicas}

Na classe (4) cor azul, práticas acadêmicas, as perguntas que geraram esta categoria foram: 1) Há no seu curso de graduação, disciplinas e/ou atividades que envolvam o ensino/aprendizagem de populações negras e quilombolas? 2) Fale sobre sua experiência durante essas disciplinas e/ou atividades. 3) O que você pensa sobre a formação específica (disciplina/atividades) que atende a população negra/quilombola?

As palavras que apresentaram maiores ocorrências foram: projeto; quilombola; saúde; levar; ação; comunidade; contato; quilombola; vivência; verificadas nos fragmentos abaixo em negritos das entrevistas: 
"a gente teve uma disciplina que envolveu este público, fizemos um trabalho em uma comunidade quilombola, foi uma ação bem breve, mas muito enriquecedor" A04.

"existe uma disciplina em um semestre, para abordar a temática, sendo insuficiente para uma formação direcionada para abordar as fragilidades desse público, percebo como insuficiente para essa formação” A05.

"A minha vivência e experiência que eu tive foi de poder viajar para uma comunidade quilombola do projeto quilombo que havia na minha instituição, no qual a gente fez atendimento, coletando o PCCU, atendimentos saúde da mulher e atendimento de enfermagem" A17.

“... visitando as comunidades quilombolas, levando o conhecimento...” A18.

Os acadêmicos participantes do estudo afirmam ter tido alguma vivência com projetos ou ações em comunidades quilombolas em suas instituições, e confirmam a existência de disciplina voltada para a saúde negra, contudo, consideram insuficiente, em decorrência do pouco tempo dedicado a questão. Muitas lacunas não foram preenchidas e o conhecimento adquirido/construído não é considerado, pelos acadêmicos suficientes para promover um cuidado efetivo com este grupo.

A formação deve garantir ao acadêmico a possibilidade de fazer conexão entre a teoria e a prática nos diferentes contextos de atendimento à saúde. Portanto, faz-se necessário ampliar as discussões sobre os processos socioculturais de produção dos agravos assim como, viabilizar ao longo da formação, um olhar sensível para o cuidado com as diferenças. Não negligenciando que pessoas/grupos diferentes necessitam de cuidados também diferenciados, a fim de garantir justiça e equidade no atendimento em saúde.

Portanto, as IES precisam considerar a possibilidade de organizar eixos temáticos de discussão com enfoque interdisciplinar. Possibilitando ao acadêmico uma maior percepção dos fenômenos que envolvem os processos de prevenção, tratamento e cura dos agravos à saúde. Garantido liberdade para aprender e condições para o fazer com a supervisão do docente. Como dito pelos acadêmicos participantes: é necessário que haja "vivência", para refletir a possibilidade de mudança de paradigma do "cuidado".

Também Ribeiro et al. (2018) discorre sobre a necessidade da formação em Enfermagem garantir a articulação entre teoria e prática, diversificação dos cenários de aprendizagem, metodologias ativas, articulação entre pesquisa, ensino e extensão, flexibilidade curricular e incorporação de atividades complementares garantindo a interdisciplinaridade, além de outros elementos, colocando o aluno como sujeito da aprendizagem, garantido assim uma formação ampla para enfrentar as adversidades no processo de cuidado.

\section{Experiências Discriminatórias}

Na classe (5) cor lilás, as perguntas que geraram esta categoria foram: Nas suas atividades de aulas práticas, vocês vivenciaram e/ou presenciaram comportamento e/ou atitudes discriminatórias por parte dos profissionais de saúde? Relate sua experiência; as palavras que apresentam maiores ocorrências: pessoa; família; presenciar; certo; aqui; Santarém; presente nas entrevistas:

“... eu não cheguei a presenciar, já cheguei a ouvir, mas nunca presenciei, eu acho que é muito importante não só na formação acadêmica, como em todas as outras formações é muito importante a pessoa ter essa consciência" A03.

“... aqui não, na instituição, mas existem algumas posturas, atitudes de colegas que são discriminatórias que procuram denegrir uma pessoa de origem tradicional” A06.

“... eu percebi da parte dela, um certo preconceito, sendo ela uma pessoa da área da saúde” A04. 
"Presenciei um certo preconceito, por parte do profissional de saúde, direcionada a uma família negra, com comportamentos discriminatórios, durante uma prática numa comunidade em Santarém” A04.

“com certeza, por que muitas pessoas, ainda tem esse preconceito, infelizmente..., em alguns lugares, as pessoas não querem ficar próximo de pessoas negras” A10.

Nos fragmentos acima, os acadêmicos relatam que já viram ou ouviram relatos de preconceitos em ambientes de saúde, demonstrando a necessidade de aprofundar investigações e discussões sobre as consequências destas atitudes nos índices de efetividades do cuidado no SUS.

A percepção de comportamentos e atitudes discriminatórias, pode ser considerada um problema de saúde pública, podendo ocasionar agravos à saúde física e mental, dificultando os vínculos entre os usuários e profissionais de saúde, o que pode gerar cuidados inadequados e uma certa dificuldade de adesão nos tratamentos em saúde (Boccolini et al., 2016).

As dificuldades de acesso às políticas públicas de saúde, as condições insalubres de vida, dificuldade de trabalho e renda, exposição a risco de discriminação ou de tratamento injusto, de todo tipo de violência e de violação de direitos sociais, ambientais, ergonômicos e a negação da cidadania, contribuem para provocar iniquidades e agravos na saúde dos negros (Matos \& Tourinho, 2018).

Daí a importância dos acadêmicos de enfermagem, refletirem sobre os aspectos históricos, políticos, culturais, sociais e epidemiológicos da saúde da população negra, conhecendo as várias formas de expressões de atitudes preconceituosa e discriminatória, com o propósito de sensibilizá-los para a detecção do preconceito nos ambientes de saúde, dotando-os de habilidades e conhecimentos capazes de atitude ética, sensível às mazelas humanas, comprometido com os deveres de cidadania em prol da promoção da saúde para toda população, inclusive a de origem negra.

\section{Considerações Finais}

O propósito do estudo foi analisar a formação dos acadêmicos de enfermagem de IES da região do oeste do Pará no tocante a assistência integral das populações negras/quilombolas, tendo em vista a PNSIPN. Percebeu-se que a formação acadêmica dos enfermeiros oferece pouca aproximação com a temática da saúde de populações negras, sendo considerada insuficiente, como também sobre as peculiaridades que envolvem o processo de adoecimento desta população.

Esta realidade pode ser reflexo da não participação dos professores na construção do Projeto Político Pedagógico e até o desconhecimento deles sobre o que se espera da formação do enfermeiro. Relatam conhecer a Política Nacional de Saúde Integral da População Negra, mas não a consideram como relevância para se discutir em sala de aula e na prática, pois ainda perdura a ideia da invisibilidade dos prejuízos em saúde da população negra. Deixando uma lacuna no ensino direcionada a esta temática. Demonstram assim, uma visão fragmentada do processo de formação e com dificuldades de garantir ao aluno conhecimentos e a compreensão ampliada das múltiplas influências cultural, social e econômica nos agravos da saúde negra.

\section{Referências}

Bagata, L. C. B. (2018). Cuidado em Saúde de mulheres ribeirinhas: relação de saber e de poder no interior da Amazônia. Santarém, PA. Orientador: Edna Ferreira Coelho Galvão. 112f. Dissertação (Mestrado em Ciências da Sociedade) - Programa de Pós-Graduação em Ciências da Sociedade, Universidade Federal do Oeste do Pará, Santarém.

Brito, L. F. et al. (2020). O nome da cor: a percepção do preconceito racial verbal pela pessoa negra e não negra. Amazônia: Science \& Health, 5(2), 15-24. Batista, L. E., Werneck, J. \& Lopes, F. (2012). Saúde da população. 2. ed. - Brasília, DF: ABPN - Associação Brasileira de Pesquisadores Negros.

Boccolini, C. S. et al. (2016). Fatores associados à discriminação percebida nos serviços de saúde do Brasil: resultados da Pesquisa Nacional de Saúde, 2013. Ciência \& Saúde Coletiva, 21, 371-8.

Brasil. (2001). Câmara de Educação Superior. Resolução CNE/CES Nº 5, de 7 de novembro de 2001.

Brasil. (2009). Portaria No 992, de 13 de maio de 2009. Política Nacional de Saúde Integral da População Negra. Brasília, DF, maio. 
Research, Society and Development, v. 10, n. 10, e150101018505, 2021

(CC BY 4.0) | ISSN 2525-3409 | DOI: http://dx.doi.org/10.33448/rsd-v10i10.18505

Brasil. (2017). Resolução No 16, de 30 de março de 2017. III Plano Operativo (2017- 2019) da Política Nacional de Saúde Integral da População Negra (PNSIPN) no âmbito do Sistema Único de Saúde. Brasília, DF, mar.

Chehuen Neto, J. A. et al. (2015). Política Nacional de Saúde Integral da População Negra: implementação, conhecimento e aspectos socioeconômicos sob a perspectiva desse segmento populacional. Ciencia \& saude coletiva, 20, 1909-1916.

De Faria, M. A. \& Da Silva, A. J. (2016). A educação das relações étnico-raciais na formação em gestão de serviços de saúde. Revista Brasileira de Ensino Superior, 2(1), 34-40.

Ganassin, F. M. H. Avaliação do processo de implementação de mudança curricular de cursos de enfermagem: um estudo em duas universidades públicas do estado de Mato Grosso do Sul. 2015. 254 p. Tese (doutorado) - Universidade Estadual de Campinas, Faculdade de Educação, Campinas, SP.

Magalhães, S. M. F. et al. (2017). Educação em Enfermagem: conceituando projeto pedagógico na visão de professores. Acta Paulista de Enfermagem, 30(3), 247-253.

Matos, C. C. \& Tourinho F. S. (2018). Saúde da População Negra: percepção de residentes e preceptores de Saúde da Família e Medicina de Família e Comunidade. Revista Brasileira de Medicina Família e Comunidade. 13 (40), 1-12.

Mendes, V. S., Costa, C. S.\& Ribeiro, R. L. R. (2017). Racismo Biológico e suas implicações no ensinar-cuidar a saúde da população negra. Revista da ABPN, 7 (16), coed, 190-213.

Minayo, M. C. de S. \& Deslandes, S. F. (2008). Caminhos do pensamento: epistemologia e método. SciELO-Editora FIOCRUZ.

Moraes, B. A. \& Costa, N. M. S. C. (2016). Compreendendo os currículos à luz dos norteadores da formação em saúde no Brasil. Rev. Enferm. USP, v. 50, n. esp., 9-16.

Keller-Franco, E., Kuntze, T. D. D. \& Costa, L. S. (2012). Inovação curricular na formação dos profissionais da saúde. Revista e-Curriculum, 9 (2).

Pereira A. S. et al. (2018). Metodologia da pesquisa científica. [free e-book]. Santa Maria/RS. Ed. UAB/NTE/UFSM.

Peres, C. R. F. B. et al. (2018). Um olhar dialético para as mudanças curriculares na formação do enfermeiro. Revista da Escola de Enfermagem da USP, 52, e03397e03397.20181.

Pinheiro, C. W. et al. (2015). O cuidado das amas-de-leite e o protagonismo do negro na história da enfermagem: uma luta por equidade. Hist. Enferm. Rev. eletrônica, 6 (1), 124-34.

Reinert, M. (1990). Alceste une méthodologie d'analyse des données textuelles et une application: Aurelia De Gerard De Nerval. Bulletin of Sociological Methodology/ Bulletin de Méthodologie Sociologique, 26 (1), 24-54.

Santana, R. A. R. et al. (2019). A equidade racial e a educação das relações étnico-raciais nos cursos de Saúde. Interface (Botucatu). 23, e170039.

Santos, R.G.; Tocantins, F.R. (2015). Equidade na assistência primária a saúde da população negra: revisão integrativa. Rev. Enferm. UFPE on line., Recife, 9, supl. 3, 7695-701.

Silva, V. O. \& Santana, P. M. M. A. (2015). Conteúdos curriculares e o Sistema Único de Saúde (SUS): categorias analíticas, lacunas e desafios; Interface (Botucatu), 19 (52), 121-132. DOI: 10.1590/1807-57622014.0017.

Soares, L. F. et al. (2020). Aspectos socioeconômicos e de condições de saúde em populações quilombolas no estado do Piauí, Brasil. Research, Society and Development, 9 (2), e73922091-e73922091.

Souza, M. A. R. et al. (2018). O uso do software IRAMUTEQ na análise de dados em pesquisas qualitativas. Rev. esc. enferm. USP, São Paulo, 52 , e03353.

Spessoto, L. R. M. M., Real, M. C. G. \& Bagnato, S. H. M. (2012). A percepção de egressos sobre as transformações curriculares ocorridas no curso de graduação em enfermagem. ETD - Educ. temat. digit. Campinas, SP 14 (2), 275-289 jul./dez. ISSN 1676-2592. 